\title{
EFICIÊNCIA DO ÍNDICE DE PERIGO DE INCÊNDIO “FÓRMULA DE MONTE ALEGRE" EM MARINGÁ-PR, NOS ANOS DE 2009 E 2010
}

\author{
Vítor Pagadigorria Zucchi ${ }^{1}$ \\ Alexandre França Tetto ${ }^{2}$
}

\section{RESUMO}

Os índices de perigo de incêndio constituem uma ferramenta fundamental para ações de proteção e defesa civil, pois permitem prever a ocorrência de incêndios florestais e subsidiam, consequentemente, a implementação de ações preventivas e de combate, protegendo a vida humana e os ecossistemas. Destarte, o presente trabalho teve como objetivo instruir sobre o uso da FMA, mostrar como são realizadas a coleta e o ajuste dos dados, os cálculos e análises comparativas, e de que forma avalia-se a eficiência deste índice. A área de estudo foi o município de Maringá-PR, tendo sido utilizado o "skill score" e a porcentagem de sucesso como parâmetros para a análise de eficiência, nos anos de 2009 e 2010. Os dados meteorológicos foram obtidos na Estação Climatológica Principal de Maringá e os dados de incêndio no sistema "SYSBM", do Corpo de Bombeiros Militar do Paraná. Constatou-se que a FMA encontra-se bem ajustada para a região, sendo que 96,62\% dos incêndios ocorreram nos dias com graus de perigo médio, alto e muito alto, enquanto o restante $(3,38 \%)$ nos graus nulo e pequeno. A FMA obteve skill score de 0,3731 e porcentagem de sucesso de $66,57 \%$, valores que permitem considerar o índice bem adequado à região e útil à Defesa Civil municipal, por subvenciar a tomada de ações preventivas e mitigatórias.

Palavras-chave: Incêndios Florestais. Risco de incêndio. FMA.

\footnotetext{
${ }^{1}$ Bombeiro Militar na Polícia Militar do Paraná ( $1^{\circ}$ Subgrupamento do $8^{\circ}$ Grupamento de Bombeiros). Bacharel em Geografia pela Universidade Estadual de Maringá. Especialista em Gestão Ambiental de Municípios, pela Universidade Tecnológica Federal do Paraná. Especialista em Proteção e Defesa Civil pela Faculdade UNINA.

${ }^{2}$ Graduado em Engenharia Florestal pela Universidade Federal do Paraná em 1997. Especialista em Prevenção e Combate a Incêndios Florestais. Mestre e Doutor em Conservação da Natureza. Diretor Administrativo da Fundação de Pesquisas Florestais do Paraná e Professor Associado do Departamento de Engenharia Florestal da UFPR.
} 


\title{
EFFICIENCY OF THE FIRE HAZARD INDEX "FORMULA DE MONTE ALEGRE" IN MARINGÁ-PR, FROM 2009 TO 2010
}

\begin{abstract}
Fire hazard indices are a fundamental tool for civil protection and defense actions, as they allow foreseeing the occurrence of forest fires and, consequently, subsidize the implementation of preventive and combat actions, protecting human life and ecosystems. Thus, this study aimed to instruct on the use of FMA, show how data collection and adjustment, comparative calculations and analyzes are carried out, and how the efficiency of this index is assessed. The study area was the city of Maringá-PR, using the "skill score" and the success percentage as parameters for the efficiency analysis, in the years 2009 and 2010. The meteorological data were obtained at the Main Climatological Station of Maringá and the fire data in the "SYSBM" system, of the Paraná Military Fire Department. It was found that the MAF is well adjusted for the region, with $96.62 \%$ of the fires occurring in the days with medium, high and very high degrees of danger, while the rest $(3.38 \%)$ in zero and small degrees. The MAF obtained a skill score of 0,3731 and a success rate of $66,57 \%$, values that make it possible to consider the index well suited to the region and useful to the municipal Civil Defense, for subsidizing the taking of preventive and mitigating actions.
\end{abstract}

Keywords: Forest fires. Fire risk. MAF. 


\section{INTRODUÇÃO}

Segundo Tetto (2012), diversas são as consequências advindas dos incêndios florestais, dentre as quais destacam-se os impactos ambientais, sociais e econômicos. Outrossim, a frequência dessas ocorrências tende a aumentar devido, principalmente, ao progressivo encurtamento da distância entre áreas com fluxo de pessoas e áreas com cobertura vegetal, as quais o autor denomina "áreas de interface urbano-rural".

Ainda no mesmo trabalho, Tetto relata que o estado do Paraná foi pioneiro no Brasil a se preocupar com a prevenção e o combate aos incêndios florestais. Isso se deu a um fato histórico e trágico ocorrido no ano de 1963, situação em que houve um incêndio florestal de gigantesca dimensão, que atingiu principalmente a região do Norte Pioneiro e Campos Gerais do Paraná, que se concentrou especialmente em áreas de propriedade da empresa Klabin S.A., sendo até hoje um dos maiores do mundo em área atingida.

Nunes et. al (2009) corroboram que a história dos incêndios florestais no Brasil começou exatamente com o incêndio de 1963. Para fins estatísticos é válido informar que nele foram atingidos cerca de 2 milhões de hectares (sendo 500.000 ha de florestas primárias), 8.000 imóveis foram destruídos, 5.700 famílias desabrigadas e 110 pessoas morreram no estado do Paraná.

Devido aos prejuízos (85\% de sua área foi impactada), a partir de 1965 a Klabin S.A. começou a estabelecer um sistema de registro e proteção contra incêndios. Atualmente, a empresa possui o mais antigo, consistente e aprimorado banco de dados sobre ocorrências de incêndios florestais no país e, desde então, fornece informações valiosíssimas para o desenvolvimento de diversas pesquisas relacionadas à temática. Foi inclusive a partir de seus dados que estudos relevantes foram realizados, a exemplo da Fórmula de Monte Alegre (FMA), tema central deste trabalho. 


\section{Revista FLAMMAE}

Revista Científica do Corpo de Bombeiros Militar de Pernambuco

Artigo Publicado no Vol.06 N.17 - Edição Jul a Dez 2020 - ISSN 2359-4829

Versão on-line disponível em: http://www.revistaflammae.com

Ainda no mesmo trabalho, Nunes et al. (2009) afirmam que o uso de um índice de perigo confiável é essencial para o planejamento eficiente das medidas de prevenção e ações de combate, evitando ou mitigando os prejuízos financeiros e ambientais. Além disso, auxilia no estabelecimento de zonas de risco, na permissão para queimas controladas em determinados períodos, na previsão do comportamento do fogo e na advertência pública do grau de perigo (SOARES; BATISTA, 2007; LOWE, 2001).

Segundo Deppe et al. (2004), a maioria dos incêndios no Paraná ocorre entre o outono e a primavera, normalmente entre maio a outubro, marcados por baixos índices pluviométricos e ocorrências de geadas. Neste contexto, $\mathrm{O}$ monitoramento de índices de perigo de incêndios e de variáveis meteorológicas permite caracterizar regiões potencialmente propícias à ocorrência de incêndios e subsidiam, além da adoção de medidas de prevenção e combate, o dimensionamento de equipes e infraestrutura, ações de manutenção, vigilância e monitoramento, entre outras.

Destarte, fica evidente a suma importância em facilitar o acesso e difundir o conhecimento a respeito dos índices de perigo de incêndio, bem como trabalhar, aprofundar e incentivar o uso dos mesmos, em virtude de tamanha validade que essa ferramenta tem para fins de proteção e defesa civil.

Diversos autores já avaliaram a eficiência de índices de perigo de incêndio nas mais variadas regiões do mundo. São frequentes os estudos que comparam a eficiência de mais de um índice para a mesma área. Reis e Torres (2018), por exemplo, avaliaram o desempenho de sete índices para as cidades do estado de Minas Gerais que faziam uso de estações meteorológicas convencionais. Neste estudo, o índice que apresentou o melhor desempenho foi o Fire Weather Index (FWI), índice canadense de previsão de incêndio (TURNER; LAWSON, 1978). Mbanze et al. (2017), por sua vez, avaliaram o desempenho dos índices de Nesterov e da Fórmula de Monte Alegre (FMA) na cidade de Lichinga, norte de Moçambique. Utilizando dados meteorológicos de temperatura, precipitação e umidade relativa, bem como dados de registro de 
Revista Científica do Corpo de Bombeiros Militar de Pernambuco

Artigo Publicado no Vol.06 N.17 - Edição Jul a Dez 2020 - ISSN 2359-4829

Versão on-line disponível em: http://www.revistaflammae.com

incêndios florestais ocorridos num período de três anos (2010 a 2012), identificaram que o índice com melhor desempenho para a região foi o de Nesterov.

Dada a relevância supracitada desta temática, o presente trabalho foi desenvolvido com o objetivo de trazer ao leitor conhecimento sobre o uso e aplicação da Fórmula de Monte Alegre, índice de perigo de incêndio desenvolvido em 1972 pelo então Professor Ronaldo Viana Soares, da Universidade Federal do Paraná, num trabalho em que foram utilizados registros de incêndios florestais ocorridos na Fazenda Monte Alegre (propriedade da Klabin) em Telêmaco Borba, coletados a partir de 1965 (SOARES, 1972).

Este pioneiro índice (o primeiro do país) subsidiou diversos outros estudos na temática de incêndios florestais no Brasil e, inclusive, foi a base para novos ajustes na fórmula originária, dando origem, por exemplo, à afamada FMA+ (Fórmula de Monte Alegre Alterada), proposta por Nunes (2005), que teve inserida a variável velocidade do vento na estrutura da FMA e foi bastante trabalhada por autores como Nunes et al. (2007 e 2010), Borges et al. (2011), White (2010), Soriano et al. (2015) entre outros.

A partir dessa leitura será possível compreender o histórico e funcionamento da FMA, quais os dados a serem coletados, os ajustes a serem feitos e, por fim, uma breve análise deste índice por meio dos parâmetros "skill score" e porcentagem de sucesso durante o período determinado para este estudo (2009 e 2010), no município de Maringá-PR. Essa metodologia correlaciona, de maneira comparativa, os resultados obtidos pela FMA, ou seja, os resultados previstos, com os dados de incêndios efetivamente observados e registrados no SYSBM, o sistema de consulta a ocorrências do Corpo de Bombeiros da Polícia Militar do Paraná. O skill score é a razão da diferença entre os acertos na previsão e o número esperado de acertos, com a diferença entre o total de dias observados e o número de dias com previsão de acertos (NUNES et al., 2010; TORRES et al., 2017). A porcentagem de sucesso, por 


\section{Revista FLAMMAE}

Revista Científica do Corpo de Bombeiros Militar de Pernambuco

Artigo Publicado no Vol.06 N.17 - Edição Jul a Dez 2020 - ISSN 2359-4829

Versão on-line disponível em: http://www.revistaflammae.com

sua vez, é a razão entre o número de acertos na previsão e o número total de observações.

Sua importância se justifica no fato de que os índices de perigo de incêndio constituem uma valiosa ferramenta à disposição dos órgãos, instituições e agentes que compõem a defesa civil, para subsidiarem o aprimoramento da previsão de períodos, condicionantes e áreas mais críticas, a tomada e intensificação de ações preventivas e de combate, a distribuição de equipes e tarefas, entre outras vantagens, garantindo a preservação de vidas humanas e dos ecossistemas.

\section{MATERIAIS E MÉTODOS}

\section{Caracterização da área de estudo}

A área de estudo definida para o presente trabalho é o município de Maringá, Paraná, sede do $1^{\circ}$ Subgrupamento do $5^{\circ}$ Grupamento de Bombeiros (FIGURA 1).

Figura 1 - Área de estudo.

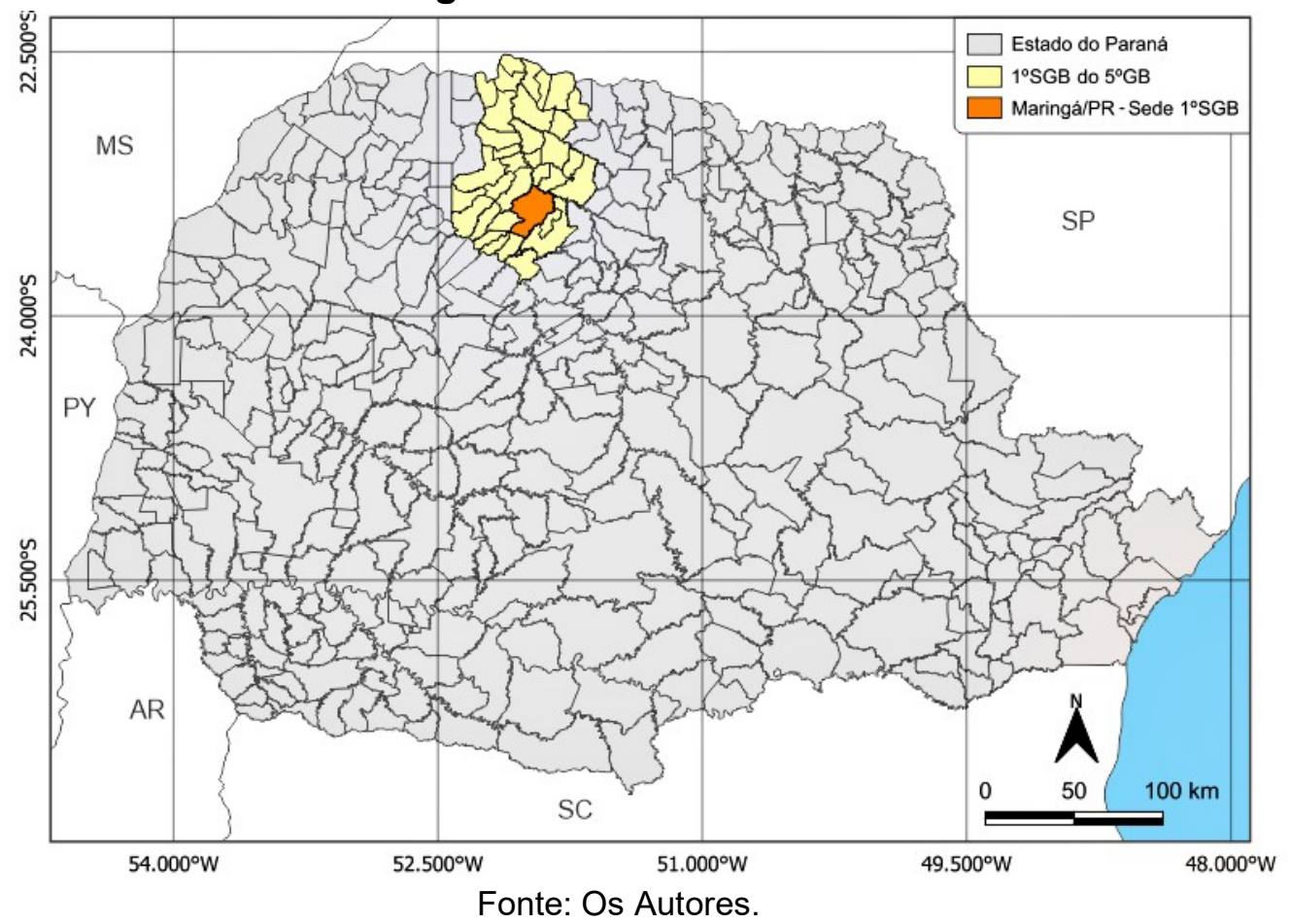


Revista Científica do Corpo de Bombeiros Militar de Pernambuco

Artigo Publicado no Vol.06 N.17 - Edição Jul a Dez 2020 - ISSN 2359-4829

Versão on-line disponível em: http://www.revistaflammae.com

Maringá é um município brasileiro de médio-grande porte situado no norte do estado do Paraná (Terceiro Planalto Paranaense) a $23^{\circ} 25^{\prime} 30^{\prime \prime} \mathrm{S}$ e $51^{\circ} 56^{\prime} 20^{\prime \prime} \mathrm{W}$, com altitudes que variam de 542 a 560 metros. Fundada em 10 de maio de 1947 e elevada à categoria de município em 14 de fevereiro de 1951, é uma cidade planejada e de urbanização recente, sendo atualmente a terceira maior cidade do Estado, com 423.666 habitantes, área de aproximadamente $487,013 \mathrm{~km}^{2}$ e densidade demográfica de 733,14 hab/km², conforme estimativa do IBGE em 2019 (BRASIL, 2020).

Conforme o Plano Municipal de Conservação e Recuperação da MataAtlântica, desenvolvido pela prefeitura municipal, a cidade apresenta uma vasta área verde remanescente de Mata Atlântica. No total são 21 áreas verdes, sendo 14 parques públicos, 01 parque particular e 06 áreas que ainda não possuem lei própria mas estão sob cuidados e políticas ambientais do município. Dessas áreas verdes 8 estão inscritas no ICMS Ecológico (MARINGA, 2011). As áreas agrícolas também têm bastante representatividade e importância no município. Fica evidente, portanto, a necessidade de atenção quanto à ocorrência e agravamento dos incêndios florestais, bem como ao uso de um índice de perigo de incêndio como ferramenta de gestão ambiental e, consequentemente, de proteção e defesa civil.

Quanto à caracterização climática, o município apresenta temperaturas médias anuais que variam de 20 a $21^{\circ} \mathrm{C}$ (sendo a média das máximas de 23 a $24{ }^{\circ} \mathrm{C}$ e as mínimas de 16 a $17^{\circ} \mathrm{C}$ ) e precipitação média anual entre 1300 e $1400 \mathrm{~mm}$ (ALVARES et al., 2014).

Cortada pela linha do Trópico de Capricórnio, a região sofre influência de vários fatores macroclimáticos, o que motiva a realização frequente de estudos de classificação climática do município, que segundo a classificação de Köppen (1884) está enquadrado no clima do tipo Cfa (subtropical, com verão quente e úmido). 
Estudos recentes, como IAPAR (2000), Maringá (2011) e Alvares et al. (2014) também encontram-se alinhados com a classificação climática de Köppen (1884) de tipo Cfa, ao caracterizarem o clima predominante da região como do tipo subtropical quente e úmido, no qual a temperatura média do mês mais frio é inferior a $18{ }^{\circ} \mathrm{C}$, enquanto a temperatura média anual é superior a $20^{\circ} \mathrm{C}$, marcado por verões chuvosos e invernos secos, porém, com mais de 30 $\mathrm{mm}$ de precipitação.

\section{Fórmula de Monte Alegre}

Cheney (1968) afirma que o uso de índices de perigo de incêndio é capaz de fornecer uma resposta em $80 \%$ dos casos, percentual mais que suficiente para justificar seu uso no planejamento do controle de incêndios florestais. As respostas, por sua vez, variam de acordo com as condições bióticas e abióticas das regiões avaliadas (em um dia ou uma sequência de dias). Por esse motivo é importante a ampliação de estudos que comparem os valores encontrados nos índices com dados reais de ocorrência, testando sua efetividade. Sob esse contexto, vários outros estudos foram desenvolvidos e usaram focos de calor como dados de comparação, a exemplo de Deppe et al. (2004), White e Ribeiro (2009), Batista (2004), entre outros.

Conforme Soares (1972) e Soares e Batista (2007), a estruturação dos índices de perigo de incêndio é baseada na relação entre elementos meteorológicos (tais como temperatura, umidade do ar, velocidade do vento e precipitação) e os incêndios florestais deflagrados e registrados. Desta forma, os resultados obtidos pelos índices refletem de maneira antecipada a probabilidade de ocorrência e a facilidade de propagação de um incêndio de acordo com as condições atmosféricas do dia ou da sequência de dias, como mencionado anteriormente. 
Neste contexto, a FMA surgiu atendendo uma necessidade momentanea mas teve seu uso ampliado e difundido, principalmente em virtude de seu funcionamento relativamente simples e eficaz, por utilizar apenas duas variáveis, quais são: a precipitação diária (em milímetros) e a umidade relativa do $\operatorname{ar}(\mathrm{em} \%)$ medida às 13 horas. A fórmula é dada por:

$$
F M A=\sum_{i=1}^{n}\left(\frac{100}{H_{i}}\right)
$$

Sendo:

FMA = Fórmula de Monte Alegre;

$\mathrm{H}=$ umidade relativa do ar em $\%$, medida às 13 horas;

$\mathrm{n}=$ número de "i” dias sem chuva maior ou igual a $13 \mathrm{~mm}$.

Maior será o grau de perigo de incêndio obtido pela FMA quanto mais longa for a série de dias com baixa umidade relativa e sem ou pouca chuva, haja vista a característica cumulativa do índice. Entretanto, o índice sofre abatimentos em seus valores dependendo da intensidade da precipitação ocorrida e pode, também, ser zerado (FMA $=0)$, nos dias em que a precipitação exceder $12,9 \mathrm{~mm}$, tornando-se nulo neste caso.

As Tabelas 1 e 2 apresentam, respectivamente, as restrições ao somatório da FMA em função da precipitação diária e a escala com os graus de perigo deste índice. 
Revista Científica do Corpo de Bombeiros Militar de Pernambuco

Artigo Publicado no Vol.06 N.17 - Edição Jul a Dez 2020 - ISSN 2359-4829

Versão on-line disponível em: http://www.revistaflammae.com

\begin{tabular}{|c|c|}
\hline $\begin{array}{l}\text { Precipitação diária } \\
\qquad(\mathrm{mm})\end{array}$ & Modificação no cálculo \\
\hline$<=2,4$ & $\begin{array}{l}\text { Sem qualquer modificação. Continua o cálculo e somatória da } \\
\text { FMA como se não houvesse precipitação. }\end{array}$ \\
\hline 2,5 a 4,9 & $\begin{array}{l}\text { FMA da véspera }-30 \%+(100 / \mathrm{H}) \text { do dia, ou seja, } \\
\qquad \mathrm{FMA}_{\text {hoje }}=0,7^{*} \mathrm{FMA}_{\text {ontem }}+\mathrm{FMA}_{\mathrm{i}(\text { hoje })}\end{array}$ \\
\hline 5 a 9,9 & $\begin{array}{l}\text { FMA da véspera }-60 \%+(100 / \mathrm{H}) \text { do dia, ou seja, } \\
\qquad \mathrm{FMA}_{\text {hoje }}=0,4^{*} \mathrm{FMA}_{\text {ontem }}+\mathrm{FMA}_{\mathrm{i}(\text { hoje })}\end{array}$ \\
\hline 10 a 12,9 & $\begin{array}{l}\text { FMA da véspera }-80 \%+(100 / H) \text { do dia, ou seja, } \\
\qquad F A_{\text {hoje }}=0,2^{*} \mathrm{FMA}_{\text {ontem }}+\mathrm{FMA}_{\mathrm{i}(\text { hoje })}\end{array}$ \\
\hline$>12,9$ & $\begin{array}{l}\text { FMA é zerada. Interrompe a somatória do dia anterior e recomeça } \\
\text { o cálculo no dia seguinte (ou no cessar da chuva acima de 12,9 } \\
\mathrm{mm} \text { ). }\end{array}$ \\
\hline
\end{tabular}

Fonte: Os Autores.

Tabela 2: Escala de Perigo da Fórmula de Monte Alegre.

\begin{tabular}{c|c}
$\begin{array}{c}\text { Intervalo de } \\
\text { Classes da FMA }\end{array}$ & $\begin{array}{c}\text { Grau de Perigo de } \\
\text { Incêndio }\end{array}$ \\
\hline$<=1$ & Nulo \\
\hline 1,1 a 3,0 & Baixo \\
\hline 3,1 a 8,0 & Moderado \\
\hline 8,1 a 20,0 & Alto \\
\hline$>20,0$ & Muito alto \\
\hline \multicolumn{2}{|c}{ Fonte: Os Autores. } \\
\hline
\end{tabular}

A interpretação do grau de perigo estimado pela FMA é feita através desta escala. Os graus de perigo de incêndio são determinados conforme o enquadramento da "FMA acumulada" de cada dia em um dos intervalos de classes da escala. 


\section{Variáveis meteorológicas}

Os dados meteorológicos (umidade relativa do ar medida às 13 horas e precipitação diária) utilizados neste trabalho foram obtidos na Estação Climatológica Principal de Maringá, situada na Universidade Estadual de Maringá.

As variáveis são coletadas nos relatórios diários emitidos na Estação, chamados de "Mapa de Observações Meteorológicas", nos quais são registradas diversas variáveis, tais como pressão atmosférica, temperatura, precipitação, umidade relativa, insolação, entre outras.

Um ponto crucial para o uso da FMA é a necessidade de se estimar a umidade relativa do ar às 13 horas. Isso é necessário pelo fato de que a maioria das estações meteorológicas do Brasil disponibilizam a umidade relativa medida às 15 horas, isto é, às 18 horas de Greenwich (fuso padrão). Para o ajuste desta variável é então necessária a aplicação da equação proposta por Nunes, Soares e Batista (2005):

$$
U R_{13}=2,451510 \cdot \mathrm{UR}_{15}^{0,796072} \quad\left(\mathrm{R}^{2}=0,8639\right)
$$

Sendo:

UR13 = umidade relativa do ar (\%), estimada para às 13 horas

UR15 = umidade relativa do ar (\%), medida às 15 horas

$\mathrm{R} 2$ = coeficiente de determinação

\section{Método "Skill Score"}

A eficiência da FMA na previsão de incêndios é determinada através do método "skill score" (SAMPAIO, 1999; TORRES et al., 2008, NUNES et al., 2010), que se utiliza de uma tabela de contingência para comparar eventos 


\section{Revista FLAMMAE}

Revista Científica do Corpo de Bombeiros Militar de Pernambuco

Artigo Publicado no Vol.06 N.17 - Edição Jul a Dez 2020 - ISSN 2359-4829

Versão on-line disponível em: http://www.revistaflammae.com

teóricos (obtidos pela FMA) com observações reais. As Tabelas 3 e 4 indicam como foram realizados os cálculos para se obter o skill score.

Tabela 3 - Tabela de Contingência

\begin{tabular}{l|c|c|c|c}
\hline \multicolumn{2}{|c|}{} & \multicolumn{2}{c|}{ OBSERVADO } & \multicolumn{1}{l}{} \\
\multicolumn{1}{l|}{ EVENTO } & Incêndio & Incêndio & Não Incêndio & Total previsto \\
\hline & Não Incêndio & $\mathrm{C}$ & $\mathrm{B}$ & $\mathrm{N} 2=\mathrm{a}+\mathrm{b}$ \\
\hline Previsto & & $\mathrm{N} 1=\mathrm{a}+\mathrm{c}$ & $\mathrm{N} 3=\mathrm{b}+\mathrm{d}$ & $\mathrm{N}=\mathrm{a}+\mathrm{b}+\mathrm{c}+\mathrm{d}$ \\
\hline Total Observado & &
\end{tabular}

Fonte: Os Autores.

Tabela 4 - Cálculo da Tabela de Contingência

\begin{tabular}{l|c|c|c|c}
\hline \multirow{2}{*}{ EVENTO } & \multicolumn{2}{c|}{ OBSERVADO } & \multirow{2}{*}{ Total previsto } \\
\cline { 3 - 5 } & Incêndio & Incêndio & Não Incêndio & 1 \\
\hline \multirow{2}{*}{ Previsto } & Não Incêndio & $\mathrm{c} /(\mathrm{a}+\mathrm{c}+\mathrm{c})$ & $\mathrm{b} /(\mathrm{b}+\mathrm{d})$ & 1 \\
\hline Total Observado & 1 & $\mathrm{~d} /(\mathrm{b}+\mathrm{d})$ & 2 \\
\hline
\end{tabular}

As variáveis necessárias para a realização dos cálculos são:

$\mathrm{N}=$ número total de observações $(\mathrm{N}=\mathrm{a}+\mathrm{b}+\mathrm{c}+\mathrm{d})$

$G=$ número de acertos na previsão $(G=a+d)$

$\mathrm{H}=$ número esperado de acertos $(H=N .(1-p) \cdot(1-q)+(N \cdot p \cdot q)$

Onde:

$\mathrm{p}=\mathrm{N} 1 / \mathrm{N}$

$\mathrm{q}=\mathrm{N} 2 / \mathrm{N}$

SS: skill score; $S S=(\mathrm{G}-\mathrm{H}) /(\mathrm{N}-\mathrm{H})$

PS: porcentagem de sucesso; $P S=(G / N) .100$ 
Revista Científica do Corpo de Bombeiros Militar de Pernambuco

Artigo Publicado no Vol.06 N.17 - Edição Jul a Dez 2020 - ISSN 2359-4829

Versão on-line disponível em: http://www.revistaflammae.com

$\mathrm{Na}$ análise de desempenho da FMA os graus de perigo nulo e pequeno são considerados como não indicativo da probabilidade de incêndios; enquanto os graus médio, alto e muito alto são considerados indicativos de probabilidade de ocorrência de incêndio.

\section{RESULTADOS E DISCUSSÃO}

Através dos dados obtidos no SYSBM e na Estação Climatológica Principal de Maringá, bem como pelos cálculos realizados, as tabelas e gráficos a seguir indicam as informações levantadas nos anos de 2009 e 2010.

Tabela 5 - Graus de Perigo definidos pela FMA

\begin{tabular}{c|c|c|c}
\hline $\begin{array}{c}\text { Graus de Perigo de } \\
\text { Incêndio }\end{array}$ & Dias de 2009 & Dias de 2010 & Total \\
\hline Nulo & 55 & 43 & $\mathbf{9 8}$ \\
\hline Pequeno & 68 & 54 & $\mathbf{1 2 2}$ \\
\hline Médio & 109 & 89 & $\mathbf{1 9 8}$ \\
\hline Alto & 99 & 84 & $\mathbf{1 8 3}$ \\
\hline Muito alto & 34 & 95 & $\mathbf{1 2 9}$ \\
\hline Total & 365 dias & 365 dias & 730 dias \\
\hline
\end{tabular}

Fonte: Os Autores.

A Tabela 5 indica quantas vezes cada grau de perigo foi registrado pela FMA ao longo do período avaliado. Observa-se que aproximadamente $70 \%$ dos dias pertenciam às classes médio, alto e muito alto, ou seja, quando a FMA previa a ocorrência de incêndios. O Gráfico 1 ilustra essa tabela para maior compreensão dos dados. 


\section{Revista FLAMMAE}

Revista Científica do Corpo de Bombeiros Militar de Pernambuco

Artigo Publicado no Vol.06 N.17 - Edição Jul a Dez 2020 - ISSN 2359-4829

Versão on-line disponível em: http://www.revistaflammae.com

Gráfico 1 - Incidência de cada grau de perigo no período avaliado.

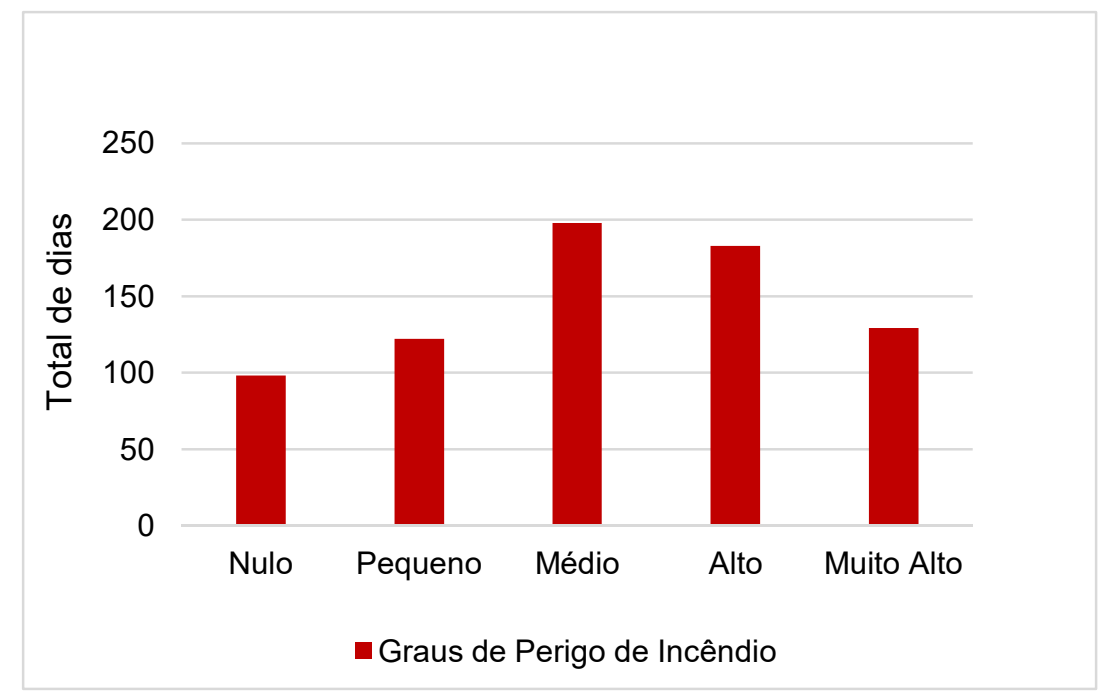

Fonte: Os Autores.

A Tabela 6 indica quantos incêndios foram registrados em cada grau de perigo determinado pela FMA. O Gráfico 2 ilustra essa tabela para maior compreensão.

Tabela 6 - Registro de ocorrências dentro de cada grau de perigo.

\begin{tabular}{c|c|c|c}
\hline $\begin{array}{c}\text { Grau de Perigo } \\
\text { de Incêndio }\end{array}$ & $\begin{array}{c}\text { Ocorrências de } \\
\text { incêndio registradas } \\
\text { em } \mathbf{2 0 0 9}\end{array}$ & $\begin{array}{c}\text { Ocorrências de } \\
\text { incêndio registradas }\end{array}$ & $\begin{array}{c}\text { Total de registros em } \\
\text { todo período }\end{array}$ \\
\hline Nulo & 8 & $\mathbf{2 0 0 9} \mathbf{~ a ~ 2 0 1 0 )}$
\end{tabular}

Fonte: SYSBM (2020). 
Revista Científica do Corpo de Bombeiros Militar de Pernambuco

Artigo Publicado no Vol.06 N.17 - Edição Jul a Dez 2020 - ISSN 2359-4829

Versão on-line disponível em: http://www.revistaflammae.com

Gráfico 2 - Ocorrências de incêndios registradas em cada grau de perigo.

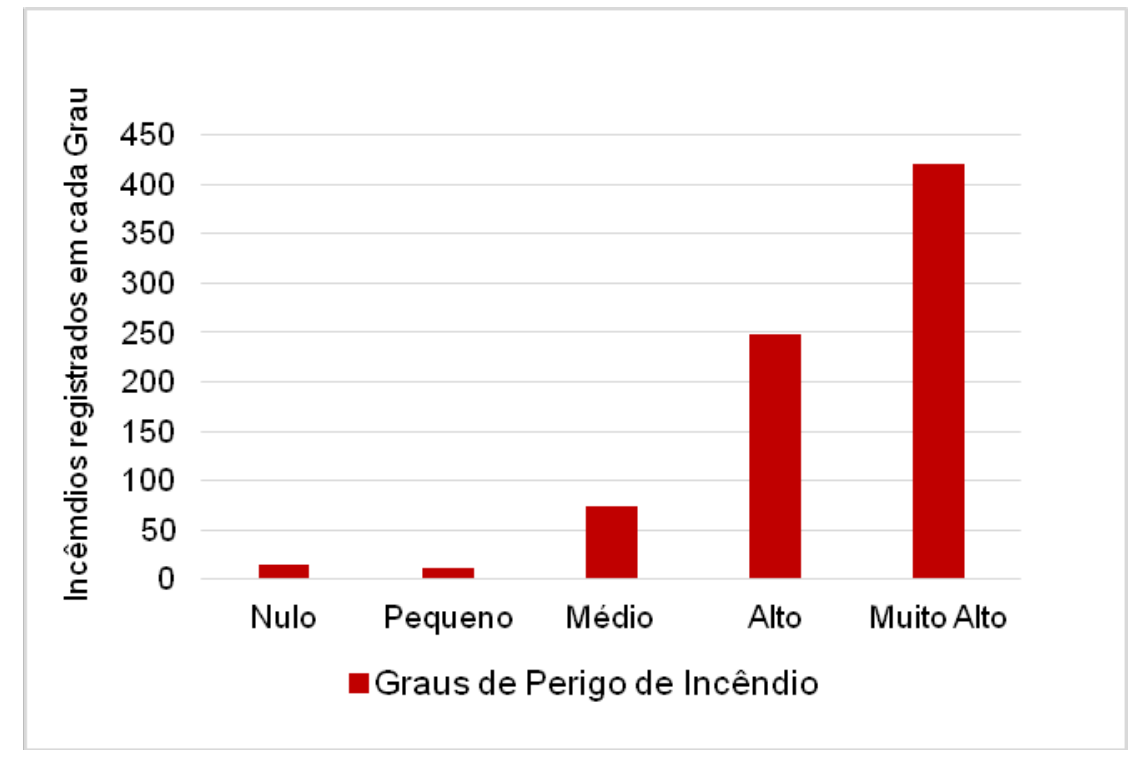

Fonte: Os Autores.

O Gráfico 2 evidencia a relação direta do aumento do número de ocorrência de incêndios conforme as classes de perigo determinadas pela FMA se tornam mais severas. Souza (2014) precisou realizar ajustes nos parâmetros de medição de grau de perigo da FMA para encontrar tal relação.

A partir das tabelas e gráficos elaborados para o período avaliado (2009 e 2010), observa-se que nos dias em que a FMA definiu os graus nulo e pequeno ocorreram 14 e 12 incêndios, respectivamente. Somando os valores o resultado equivale, aproximadamente, a 3,38\% das 719 ocorrências registradas no período, valor que é ínfimo perto do total constatado. Em contrapartida, nos dias em que a FMA definiu os graus médio, alto e muito alto, a representatividade percentual foi de aproximadamente $9,62 \%, 32,38 \%$ e $54,61 \%$, respectivamente. O resultado da soma dos três graus de perigo equivale, aproximadamente, a 96,62\% das ocorrências registradas no período. Esses percentuais evidenciam a eficiência da FMA e o quanto a fórmula está ajustada para a região. Importa relembrar que, segundo o método skill score, a FMA indica a probabilidade de incêndios quando registra, exatamente, os três graus supracitados. 
Revista Científica do Corpo de Bombeiros Militar de Pernambuco

Artigo Publicado no Vol.06 N.17 - Edição Jul a Dez 2020 - ISSN 2359-4829

Versão on-line disponível em: http://www.revistaflammae.com

As Tabelas 7, 8 e 9 apresentam, respectivamente, as variáveis $a, b, c$, e $d$ obtidas no período analisado e o cálculo dos valores de skill score e porcentagem de sucesso.

Tabela 7 - Tabela de Contingência, 2009 a 2010.

\begin{tabular}{|c|c|c|c|c|}
\hline \multirow{2}{*}{\multicolumn{2}{|c|}{ EVENTO }} & \multicolumn{2}{|c|}{ OBSERVADO } & \multirow[b]{2}{*}{ Total previsto } \\
\hline & & Incêndio & Não Incêndio & \\
\hline & Incêndio & $a=285$ & $\mathbf{b}=225$ & $\mathbf{N} 2=510$ \\
\hline Previsto & Não Incêndio & $\mathbf{c}=19$ & $d=201$ & N4 $=220$ \\
\hline \multicolumn{2}{|c|}{ Total Observado } & $\mathbf{N} 1=304$ & N3 $=426$ & $\mathbf{N}=730$ \\
\hline
\end{tabular}

Tabela 8 - Cálculo da Tabela de Contingência, 2009 a 2010

\begin{tabular}{|c|c|c|c|c|}
\hline \multirow{2}{*}{\multicolumn{2}{|c|}{ EVENTO }} & \multicolumn{2}{|c|}{ OBSERVADO } & \multirow[b]{2}{*}{ Total previsto } \\
\hline & & Incêndio & Não Incêndio & \\
\hline \multirow{4}{*}{ Previsto } & Incêndio & $a /(a+c)=0,9375$ & $b /(b+d)=$ & 1 \\
\hline & & & 0,528169014 & \\
\hline & Não Incêndio & $c /(a+c)=0,0625$ & $b /(b+d)=$ & 1 \\
\hline & & & 0,471830986 & \\
\hline \multicolumn{2}{|c|}{ Total Observado } & 1 & 1 & 2 \\
\hline
\end{tabular}

Fonte: Os Autores. 
Revista Científica do Corpo de Bombeiros Militar de Pernambuco

Artigo Publicado no Vol.06 N.17 - Edição Jul a Dez 2020 - ISSN 2359-4829

Versão on-line disponível em: $\underline{\text { http://www.revistaflammae.com }}$

Tabela 9 - Variáveis calculadas a partir dos dados dispostos nas Tabelas de

Contingências e resultados de Skill Score e Porcentagem de Sucesso, 2009 a 2010.

\begin{tabular}{l|c}
\hline \multicolumn{1}{c|}{ VARIÁVEL } & RESULTADO \\
\hline$p=N 1 / N$ & 0,416438356 \\
\hline$q=N 2 / N$ & 0,698630137 \\
\hline$G=a+d$ & 486 \\
\hline$H=N .(1-p) \cdot(1-q)+(N \cdot p \cdot q)$ & 340,767123238 \\
\hline$S S=(G-H) /(N-H)$ & $\mathbf{0 , 3 7 3 1 2 5 9 2 4}$ \\
\hline$P S=(G / N) \cdot 100$ & $\mathbf{6 6 , 5 7 5 3 4 2 4 6 5}$
\end{tabular}

Fonte: Os Autores.

A Tabela 9 apresentou o cálculo para obtenção dos valores de skill score $(0,3731)$ e porcentagem de sucesso $(66,57 \%)$. Tais valores permitem concluir que a FMA está bem ajustada para a região, principalmente por conta do período em que foi avaliada.

Estudos realizados por Zucchi e Bravo (2013) e Mari (2015), também na cidade de Maringá-PR, apontam que os anos de 2009 e 2010 tiveram características climáticas muito divergentes entre si. Altos índices de temperatura e insolação, baixos índices pluviométricos e baixíssimos índices de umidade relativa foram registrados em 2010 (ZUCCHI e BRAVO, 2013). Os valores de umidade relativa neste ano foram tão baixos que no dia 13 de setembro atingiu 10,6\%, o menor índice nos últimos 11 anos até então. Conforme a classificação da Organização Mundial da Saúde (OMS), este valor colocava a cidade em estado de emergência, visto que seu índice estava abaixo dos 12\% (MARINGÁ, 2010). Em contrapartida, o ano de 2009 foi o que apresentou o maior excedente hídrico no período de 2000 a 2011 (MARI, 2015). 
Revista Científica do Corpo de Bombeiros Militar de Pernambuco

Artigo Publicado no Vol.06 N.17 - Edição Jul a Dez 2020 - ISSN 2359-4829

Versão on-line disponível em: http://www.revistaflammae.com

As consequências dessas condições meteorológicas distintas podem ser observadas na Tabela 6 , que apresenta o total de incêndios em cada ano e evidencia a grande diferença numérica de ocorrências entre 2009 (262 incêndios) e 2010 (507 incêndios), que equivale a um aumento de 93,5\% de um ano para o outro.

Por fim, ao desafiar a assertividade da FMA avaliando sua eficiência neste período, os valores de 0,3731 para SS e $66,57 \%$ para a $P S$ evidenciaram a adequabilidade da FMA para o município de Maringá, principalmente quando comparados com valores obtidos em outros estudos.

Tais resultados se mostram superiores, por exemplo, aos encontrados por Rodriguez et al. (2017) na cidade de Pinar del Rio (Cuba) com o índice FPR (Fórmula de Pinar del Rio), o qual obteve SS de 0,1174 e PS de 63\%, bem como superiores aos obtidos por Rodriguez et al. (2012) com a FMA+ (Fórmula de Monte Alegre Alterada) na Empresa Florestal de Macurije, em Cuba também, com valores de SS de 0,0737 e PS de 57\%.

Mbanze et al. (2017), ao compararem a eficiência dos índices de Nesterov e FMA em Lichinga (Moçambique), obtiveram valores de SS de 0,11 e $P S$ de $44,82 \%$ para o índice de Nesterov e $S S$ de 0,07 e $P S$ de $35,62 \%$ para a FMA, resultados também menos satisfatórios que a FMA calculada para Maringá.

Outro estudo avaliativo da eficiência da FMA foi realizado por Kovalsky et al. (2014), na cidade de Ponta Grossa-PR, no período de 2006 a 2013. Com um total de 1596 ocorrências de incêndios no período avaliado a FMA obteve valores de SS 0,2234 e uma PS de 53,86\%.

Souza (2014), por sua vez, ao avaliar a eficiência da FMA e da FMA+ no município de Lages-SC precisou realizar ajustes nos parâmetros de medição de grau de perigo dos índices para então encontrar valores de SS 0,2146 e PS $67,41 \%$ para a FMA e SS 0,1883 e PS $63,53 \%$ para a FMA+. 


\section{CONCLUSÕES}

Observou-se que o desempenho da FMA foi bastante satisfatório para a região, especialmente em virtude do período avaliado, com valores que superaram resultados obtidos em diversos outros estudos que avaliaram a FMA como também outros índices.

O estudo e a análise de eficiência deste índice mostraram que, apesar de sua característica frugal, o mesmo foi assertivo e aplicável para a região avaliada. A FMA mostra-se, portanto, como um índice extremamente simples para se compreender e aplicar, tornando-se, efetivamente, uma verdadeira ferramenta à disposição da sociedade.

Como fechamento, pode-se concluir que o trabalho foi capaz de suscitar e ampliar o interesse em relação ao uso dos índices de perigo de incêndio, trazendo subsídios e estímulo a novas pesquisas nesta e nas demais unidades do Corpo de Bombeiros do Estado, de modo que possam testar a eficiência da FMA em suas áreas de abrangência e até mesmo compará-la com outros índices bastante conhecidos, tais como Nesterov, Telicyn, FWI, FMA+ entre outros, a fim de encontrar o mais ajustado para cada região.

\section{AGRADECIMENTOS}

À Estação Climatológica Principal de Maringá e ao $1^{\circ}$ Subgrupamento do $5^{\circ}$ Grupamento de Bombeiros, pela cessão dos dados meteorológicos e de incêndio, respectivamente. 


\section{REFERÊNCIAS}

ALVARES, C. A; STAPE, J. L.; SENTELHAS, P. C.; GONÇALVES, J. L. M.; SPAROVEK, G. Koppen's climate classification map for Brazil. Meteorologische Zeitschrift, Vol. 22, No. 6, 711-728, Stuttgart, Alemanha. 2014.

BATISTA, A. C. Detecção de incêndios florestais por satélites. Floresta, [S.I], ago. 2004.

BRASIL, Instituto Brasileiro de Geografia e Estatística. 2020. IBGE, Brasil/Paraná/Maringá. Disponível: https://cidades.ibge.gov.br/brasil/pr/maringa/panorama Acesso: 27/fev/2020.

CHENEY, N. P. Predicting behavior with danger tables. Australian Forestry. $p$. 71-79. 1968.

DEPPE, F.; PAULA, E.V.; MENEGHETTE, C.R.; VOSGERAU, J. Comparação de índice de risco de incêndio florestal com focos de calor no Estado do Paraná. Floresta 34:119-126, 2004.

KÖPPEN, W. Die Warmezonen der Erde, nach der Dauer der heissen, gemassigten und kalten Zeit und nach der Wirkung der Wa"rme auf die organische Welt betrachtet. - Meteorol. Z. 1, 215-226. 1884.

KOVALSYKI, B.; TETTO, A. F.; BATISTA, A. C.; SOUSA, N. J.; TAKASHINA, I. K. Avaliação da eficiência da Fórmula de Monte Alegre para o município de Ponta Grossa - PR. Enciclopédia Biosfera, v. 10, p. 208-214, 2014.

LOWE, J. D. Wildland firefighting practices. 348p. Albany, NY, Delmar. 2001.

MARI, A. P. C. Disponibilidade hídrica e classificação climática como auxílio no planejamento ambiental para o município de Maringá-Paraná. 24p. Monografia (Esp. em Projetos Sustentáveis, Mudanças Climáticas e Gestão Corporativa de Carbono) - Programa de Educação Continuada em Ciências Agrárias. Universidade Federal do Paraná. Curitiba. 2015.

MARINGÁ. Secretaria Municipal do Meio Ambiente. Plano Municipal de Conservação e Recuperação da Mata Atlântica, Maringá-Paraná. 2011. 


\section{Revista FLAMMAE}

Revista Científica do Corpo de Bombeiros Militar de Pernambuco

Artigo Publicado no Vol.06 N.17 - Edição Jul a Dez 2020 - ISSN 2359-4829

Versão on-line disponível em: http://www.revistaflammae.com

Disponível: http://www.maringa.pr.gov.br/mata_atlantica/plano.pdf Acesso:

$17 / \mathrm{fev} / 2020$

MARINGÁ. Gazeta do Povo. Maringá tem a umidade relativa do ar mais baixa dos últimos 11 anos. 2010. Disponível: https://www.gazetadopovo.com.br/vidae-cidadania/maringa-tem-a-umidade-relativa-do-ar-mais-baixa-dos-ultimos-11anos-25omx8jjxkxp26in8gylsrrda/ Acesso: 19/fev/2020.

MBANZE, A. A.; BATISTA, A. C.; TETTO, A. F.; ROMERO, A. M.; MUDEKWE, $J$. Desempenho dos índices de Nesterov e Fórmula de Monte Alegre no Distrito de Lichinga, norte de Moçambique. Ciência Florestal, Santa Maria, v.27, n. 2, p. 687-696, Junho 2017.

NUNES, J. R. S.; FIER, I. S. N.; SOARES, R. V.; BATISTA, A. C. Desempenho da Fórmula de Monte Alegre (FMA) e da Fórmula de Monte Alegre Alterada $(\mathrm{FMA}+)$ no Distrito Florestal de Monte Alegre. Floresta, Curitiba, PR, v. 40, n. 2, p. 319-326, abr./jun. 2010.

NUNES, J. R. S.; SOARES, R. V.; BATISTA, A. C. Análise da Fórmula de Monte Alegre Alterada $\left(\mathrm{FMA}^{+}\right)$para o Estado do Paraná. Floresta, Curitiba, PR, v. 39, n. 3, p. 473-484, jul./set. 2009

NUNES, J. R. S.; SOARES, R. V.; BATISTA, A. C. Ajuste da Fórmula de Monte Alegre Alterada - FMA+ para o estado do Paraná. Floresta, Curitiba, v. 37, n. 1, p. 1-14, 2007.

NUNES, J. R. S. FMA+ - Um Novo Índice de Perigo de Incêndios Florestais para o Estado do Paraná - Brasil. Curitiba, $150 \mathrm{f}$. Tese (Doutorado em Engenharia Florestal) - Setor de Ciências Agrárias, Universidade Federal do Paraná, 2005.

REIS, T. L.; TORRES, F. T. P. Avaliação da eficiência de índices de perigo meteorológico de incêndios florestais para o Estado de Minas Gerais. Revista Brasileira de Climatologia. p. 311-319. nov. 2018.

RODRIGUEZ, Y. C.; RODRIGUEZ, M. P. R.; BATISTA, A. C.; BECERRA, L. W. M.; TETTO, A. F. Diseño de un índice de peligro de incendio forestal para la Provincia de Pinar del Rio, Cuba. Floresta, Curitiba, v. 47, p. 65-74, 2017.

RODRÍGUEZ, M.P.; SOARES, R.V.; BATISTA, A.C.; TETTO, A.F.;SIERRA, C.A.; RODRÍGUEZ, Y.C. Ajuste e desempenho dos índices de perigo de 
Revista Científica do Corpo de Bombeiros Militar de Pernambuco

Artigo Publicado no Vol.06 N.17 - Edição Jul a Dez 2020 - ISSN 2359-4829

Versão on-line disponível em: http://www.revistaflammae.com

incêndios Nesterov, FMA e FMA+ na empresa florestal Macurije, Cuba.

Floresta, Curitiba, v. 42. n. 4,p. 651-660, 2012.

SAMPAIO, O. B. Análise da eficiência de quatro índices na previsão de incêndios florestais para a região de Agudos - SP. 157 f. Tese (Doutorado em Ciências Florestais) - Setor de Ciências Agrárias, Universidade Federal do Paraná, Curitiba, 1999.

SOARES, R. V.; BATISTA, A. C. Incêndios Florestais: controle, efeitos e uso do fogo. Curitiba. 2007. v. 1. 264 p.

SOARES, R.V. Determinação de um índice de perigo de incêndios para a região centro-paranaense, Brasil. 72 p. Dissertação (Mestrado em Ciências Florestais) - Centro Tropical de Ensino e Investigação, Instituto Interamericano de Ciências Agrícolas OEA, Turrialba, Costa Rica. 1972.

SORIANO, B. M. A.; DANIEL, O.; SANTOS, S. A.; Eficiência de índices de risco de incêndios para o pantanal sul-matogrossense. Ciência Florestal, Santa Maria, v. 25, n. 4, p. 809-816, out.-dez., 2015.

SOUZA, J. I. Comportamento e ajustes dos índices de perigo de incêndio FMA e FMA+ para o município de Lages-SC. 93 f. Dissertação (Mestrado em Engenharia Florestal) - Universidade Estadual de Santa Catarina. Lages, 2014.

TETTO, A. F. Comportamento histórico dos incêndios florestais na Fazenda Monte Alegre no período de 1965 a 2009. Tese (Doutorado em Engenharia Florestal) - Universidade Federal do Paraná, Curitiba, 2012.

TORRES, F. T. P.; LIMA, G. S.; MARTINS, S. V.; VALVERDE, S. R. Analysis of efficiency of fire danger indices in forest fire prediction. Árvore, v.41(2), p.1-10, 2017.

TORRES, F. T. P. et al. Incêndios em vegetação na área urbana de Juiz de Fora - Minas Gerais. Ubá: Editora Geographica Consultoria, Estudos e Projetos Ambientais, 65p. 2008.

TURNER, J. A.; LAWSON, B. D. Weather in the Canadian Forest Fire Danger Rating System. A user guide to national standards and practices. Victoria, British Columbia: Environment Canada, Centre de recherches forestières du Pacifique. 1978. 
WHITE, B. L. A.; Incêndios Florestais no Parque Nacional Serra de

Itabaiana - Sergipe. $144 \mathrm{f}$. Dissertação (Mestrado em Desenvolvimento e Meio Ambiente). Universidade Federal de Sergipe, São Cristóvão, 2010.

WHITE, Benjamin; RIBEIRO, Adauto; Utilização da FMA e da FMA+ como instrumento de medida de risco de fogo nos municípios que formam o Parque Nacional Serra de Itabaiana. In: III Congresso Latino Americano De Ecologia, 3 , Anais. São Lourenço. 2009. p. 1-3.

ZUCCHI, V. P.; BRAVO, J. V. M. A Influência dos Elementos Climáticos na Ocorrência de Incêndios na Região de Maringá-PR, nos Anos de 2009/2010. Revista Brasileira de Geografia Física, [S.I.], v. 6, n. 3, p. 417-426, nov. 2013. 